\title{
Modulation of Apoptosis by Natural Products for Cancer Therapy
}

Author

Affiliation
Simone Fulda

Children's Hospital, Ulm University, Ulm, Germany
Key words

- natural products

- apoptosis

- cancer therapy received January 13, 2010

revised March 26, 2010

accepted April 19, 2010

\section{Bibliography}

DOI http://dx.doi.org/

10.1055/s-0030-1249961

Published online May 19, 2010

Planta Med 2010; 76:

1075-1079 ๑ Georg Thieme

Verlag KG Stuttgart · New York

ISSN 0032-0943

\section{Correspondence}

\section{Prof. Simone Fulda}

University Children's Hospital

Eythstrasse 24

89075 Ulm

Germany

Phone: + 4973150057034

Fax: + 4973150057058

simone.fulda@uniklinik-ulm.de

\section{Abstract \\ $\nabla$}

Natural products can exhibit many beneficial effects on human health. As far as cancer is concerned, naturally occurring compounds have been reported to prevent tumorigenesis and also to suppress the growth of established tumors. As cancer cells have evolved multiple mechanisms to resist the induction of programmed cell death (apoptosis), the modulation of apoptosis signaling pathways by natural compounds has been demonstrated to constitute a key event in these antitumor activities. This review presents some examples of how apoptosis pathways are targeted by selected naturally occurring agents and how these events can be exploited for cancer therapy.

\section{Introduction}

\section{$\nabla$}

Over the last decades, natural compounds have attracted considerable attention as cancer chemopreventive agents and also as cancer therapeutics [1]. Among their various biological activities, natural products can modulate apoptosis signaling pathways. Apoptosis or programmed cell death is an evolutionary highly conserved intrinsic death program that plays a key role in maintaining tissue homeostasis during development and in adult life [2]. Consequently, too little apoptosis can promote tumorigenesis even without an increase in proliferation [3]. Evasion of apoptosis is a characteristic feature of human cancers that promotes tumor formation and progression $[3,4]$. Additionally, the inability of most cancers to undergo apoptosis in response to appropriate stimuli is a key cause of treatment failure and presents one of the major, yet unsolved problems in oncology $[3,4]$. Therefore, new concepts are required to overcome cancer resistance to conventional treatment approaches. Since natural compounds can modulate apoptosis pathways that are frequently blocked in human cancers, these compounds may provide novel opportunities for cancer drug development.

\section{Core Apoptosis Signal Transduction Pathways}

Two major apoptosis pathways, i.e., the receptor (extrinsic) pathway and the mitochondrial (intrinsic) pathway, eventually result in the activation of caspases, a family of enzymes that act as death effector molecules in various forms of cell death $[5,6]$. In the receptor pathway, ligation of death receptors of the tumor necrosis factor (TNF) receptor superfamily, for example, CD95 (APO-1/Fas) or TNF-related apoptosis inducing ligand (TRAIL) receptors, by their cognate natural ligands or by agonistic antibodies initiates receptor oligomerization followed by the recruitment of adaptor molecules such as FADD and caspase8 to the activated death receptors leading to the activation of caspase-8 [7]. Once activated, caspase- 8 either directly cleaves and thereby activates effector caspase- 3 or alternatively, cleaves Bid into tBid $[8,9]$. Bid is a BH3-only protein of the Bcl-2 family, which upon cleavage translocates as tBid to mitochondria to stimulate mitochondrial outer membrane permeabilization [9]. Thus, Bid links the receptor to the mitochondrial pathway and can initiate a mitochondrial amplification loop upon its caspase-mediated proteolytic processing [9]. Initiation of the mitochondrial (intrinsic) pathway of apoptosis constitutes a point of no return in various models of apoptosis, eventually resulting in the activation of caspases [10] In the mitochondrial pathway, the release of mi- 
tochondrial intermembrane space proteins such as cytochrome c or second mitochondria-derived activator of caspase (Smac)/direct IAP binding protein with low pI (DIABLO) into the cytosol triggers a common prefinal stage of apoptosis that is characterized by the activation of effector caspases [11]. To this end, cytochrome c promotes caspase- 3 activation via the formation of the apoptosome complex that contains besides cytochrome c also Apaf- 1 and caspase- 9 and results in the activation of caspase- 9 and subsequently caspase-3 [11]. Smac/DIABLO promotes activation of caspases-3, -7 and -9 by binding to and antagonizing "inhibitor of apoptosis" (IAP) proteins [11]. IAP proteins are a family of endogenous caspase inhibitors and comprise eight human analogues, including XIAP, c-IAP1, c-IAP2, survivin and livin/melanoma-IAP (ML-IAP) [12].

There are various intervention points that control cell death pathways, since inappropriate induction of apoptosis may have detrimental effects on the cell's survival [3]. For example, proand anti-apoptotic proteins of the Bcl-2 family play an important role in the regulation of the mitochondrial pathway [9]. The antiapoptotic Bcl-2 family members comprise, e.g., Bcl-2, Bcl-XL and Mcl-1, while the multidomain proteins Bax and Bak and BH3 domain-only proteins such as Bid, Bim, Noxa and Puma belong to the pro-apoptotic molecules [9]. The ratio of anti-apoptotic versus pro-apoptotic Bcl-2 family proteins rather than the expression of one single family member is considered to control apoptosis sensitivity. These anti-apoptotic control points that prevent accidental cell death under physiological conditions are often deregulated in cancers and may confer drug resistance. Besides apoptosis, several non-apoptotic modes of cell death have also been identified in recent years, including necrosis, autophagy or mitotic catastrophe [13].

\section{Examples of Natural Compounds that Induce Apoptosis in Cancer Cells (O Table 1, Fig. 2)

\section{Betulinic acid}

Betulinic acid [3ß-hydroxy-lup-20(29)-en-28-oic acid] is a pentacyclic triterpenoid, which naturally occurs, for example, in the bark of white birch trees and has been identified to stimulate the mitochondrial apoptosis pathway preferentially in cancer cells [14-16]. In a cell-free system, betulinic acid has been demonstrated to directly cause mitochondrial outer membrane permeabilization and cytochrome c release in a Bcl-2 or Bcl- $\mathrm{X}_{\mathrm{L}}$-dependent manner, yet independently of caspases $[14,15,17,18]$. Betu- linic acid was also reported in various models to induce apoptosis in a p53-independent fashion, including chemotherapy-refactory cases $[15,19-24]$, indicating that betulinic acid may bypass some types of drug resistance.

\section{Resveratrol}

Resveratrol ( $\bullet$ Fig. 1) is another natural compound that is present in several dietary items, e.g., in grapes and red wine [25]. Chemically, resveratrol belongs to the group of polyphenolic phytoalexins [25]. Resveratrol has been described to interfere with mitochondrial functions by inhibiting mitochondrial ATP synthesis through its binding to $\mathrm{F}_{1}$-ATPase [25]. In addition, resveratrol can antagonize anti-apoptotic proteins that prevent the induction of apoptosis in cancer cells. For example, resveratrol has been reported to induce p53-independent upregulation of p21, p21-triggered cell cycle arrest and subsequently cell cycle-dependent depletion of the anti-apoptotic protein survivin, thereby sensitizing cancer cells to TRAIL-induced apoptosis [26]. Besides survivin, resveratrol has also been demonstrated to suppress expression levels of additional anti-apoptotic proteins, for example, Bcl- $x_{\mathrm{L}}$ and Mcl-1 [27]. The antitumor activities of resveratrol have also been linked to its ability to interfere with the phosphatidylinositol-3 kinase (PI-3K)/AKT and the MAPK pathways [28-31], two key survival cascades that are frequently aberrantly activated in human cancers [32]. To improve the targeting to mitochondria, resveratrol has been coupled to the membrane-permeant lipophilic TPP cation [33]. Compared to the parent compound, mitochondria-targeted resveratrol derivatives, i.e., 4-triphenylphosphoniumbutyl-4'-O-resveratrol iodide, accumulate in mitochondria and may provide the basis for the design of more selective and potent resveratrol derivatives [33].

\section{Vitamin E analogues}

Vitamin E analogues, for example, $\alpha$-tocopheryl succinate ( $\alpha$-TOS), have also been reported to selectively trigger mitochondrial apoptosis in tumor cells [34]. Recently, evidence has been provided that $\alpha$-TOS directly interacts with both ubiquinonebinding sites of the respiratory complex II, leading to the displacement of ubiquinone from complex II and subsequently to ROS generation [35]. $\alpha$-TOS not only targets cancer cells but also endothelial cells [36], which may contribute to its potent antitumor activity. Experiments performed in endothelial cells that were depleted of mitochondrial DNA confirmed the key role of the intrinsic apoptosis pathway to $\alpha$-TOS-mediated cytotoxicity [36]. In addition to $\alpha$-TOS, a series of vitamin $\mathrm{E}$ analogues has

\begin{tabular}{|c|}
\hline Compound \\
\hline$\alpha-\operatorname{TOS}$ \\
\hline ATRA \\
\hline Betulinic acid \\
\hline CD437 \\
\hline Gossypol (AT-101) \\
\hline 2-Methoxyestradiol \\
\hline Methyl jasmonate \\
\hline PEITCs \\
\hline
\end{tabular}

Resveratrol

\begin{tabular}{ll} 
Target/Mode of action & References \\
Ubiquinone-binding sites in respiratory complex II & {$[35]$} \\
\hline ANT ligand & {$[47]$} \\
PTPC & {$[15]$} \\
\hline PTPC & {$[45,46]$} \\
\hline Inhibitor of BCl-2, BCl-X $\mathrm{L}, \mathrm{BCl}-\mathrm{W}, \mathrm{Mcl}-1$ & {$[41,44,57]$} \\
SOD inhibition & {$[50]$} \\
\hline Interferes with HK2/VDAC interaction & {$[56]$} \\
\hline ROS regulator (GSH depletion, GPX inhibition) & {$[48]$} \\
\hline F-ATPase & {$[25]$}
\end{tabular}

Abbreviations: $\alpha$-TOS, $\alpha$-tocopheryl succinate; ANT, adenine nucleotide translocase; ATRA, all-trans-retinoic acid; CD437, 6-[3-(1-adamantyl)-4-hydroxyphenyl]-2-naphtalene carboxylic acid; GPX, glutathione peroxidase; GSH, reduced glutathione; HK, hexokinase; PBR, peripheral benzodiazepine receptor; PEITCs, phenyl ethyl isothiocyanates; PTPC, permeability transition pore complex; ROS, reactive oxygen species; SOD, superoxide dismutase; VDAC, voltage-dependent anion channel
Table 1 Examples of apoptosis targeting natural compounds. 


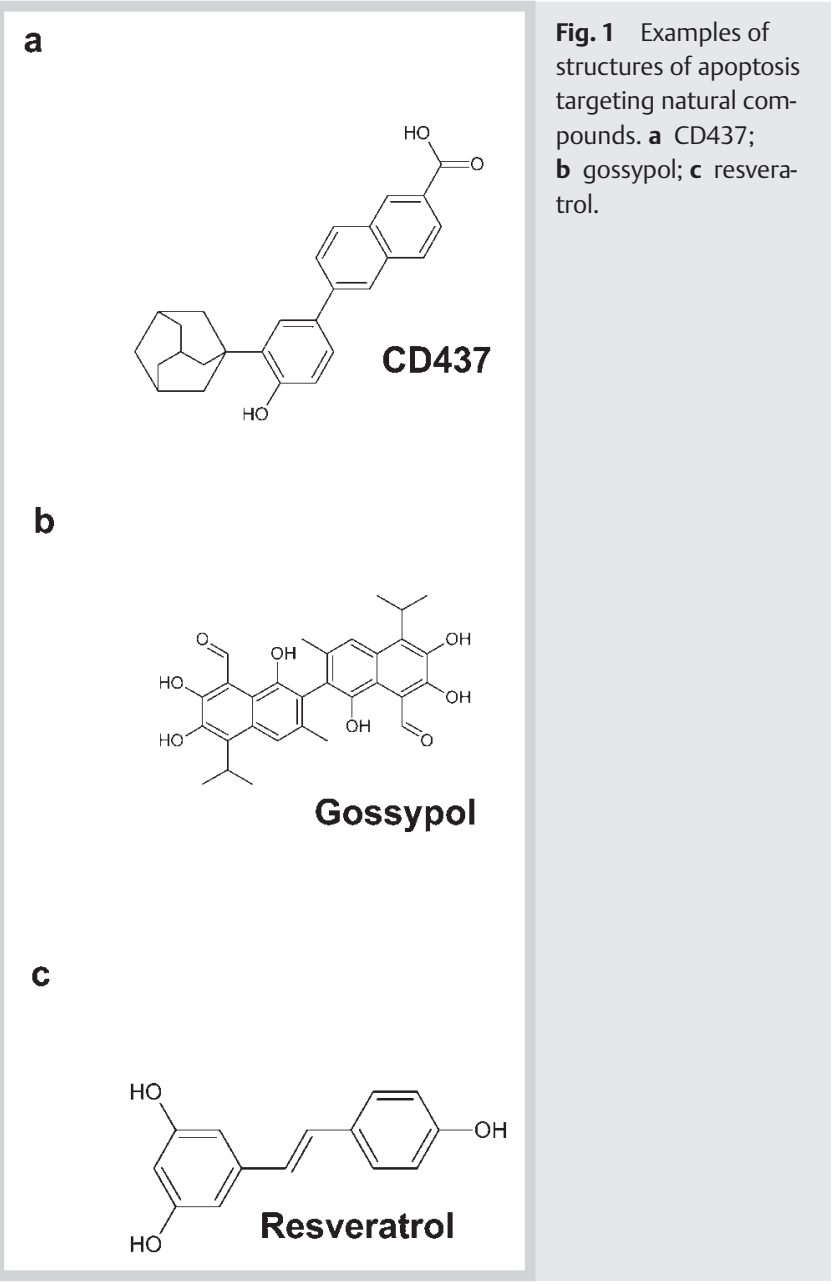

been synthesized, e.g., a non-hydrolyzable ether-linked acetic acid derivative of $\alpha$-TOH (i.e., $\alpha$-TEA) [37-39]. These derivatives proved to harbor improved antitumor activity in some (but not all) cancers compared to the parent compound [37-39]. Of special interest is also the reported tumor selectivity of $\alpha$-TOS [40], which has been linked to its ester structure.

\section{BH3 mimetics}

Gossypol (AT-101) (๑ Fig. 1), a polyphenolic aldehyde that naturally occurs in the cotton plant [41], has been demonstrated to simultaneously antagonize several anti-apoptotic Bcl-2 proteins, which interfere with mitochondrial outer membrane permeabilization, including Bcl-2, Bcl- $\mathrm{X}_{\mathrm{L}}, \mathrm{Bcl}-\mathrm{W}$ and $\mathrm{Mcl}-1$ [42]. The derivative apogossypol has been described to exhibit superior antitumor activity combined with reduced toxicity compared to gossypol [43]. It is interesting to note that gossypol showed clinical activity as monotherapy in a phase I trial for the treatment of prostate cancer [44] and is currently being evaluated as mono- or combination therapy in several malignancies.

\section{Compounds targeting permeability transition pore complex (PTPC)}

The permeability transition pore complex (PTPC) is a highly dynamic supramolecular structure, which comprises the voltagedependent anion channel (VDAC) in the outer membrane, the peripheral benzodiazepine receptor (PBR, also known as TSPO, translocator protein of $18 \mathrm{kDa}$ ) in the outer membrane, the ad-

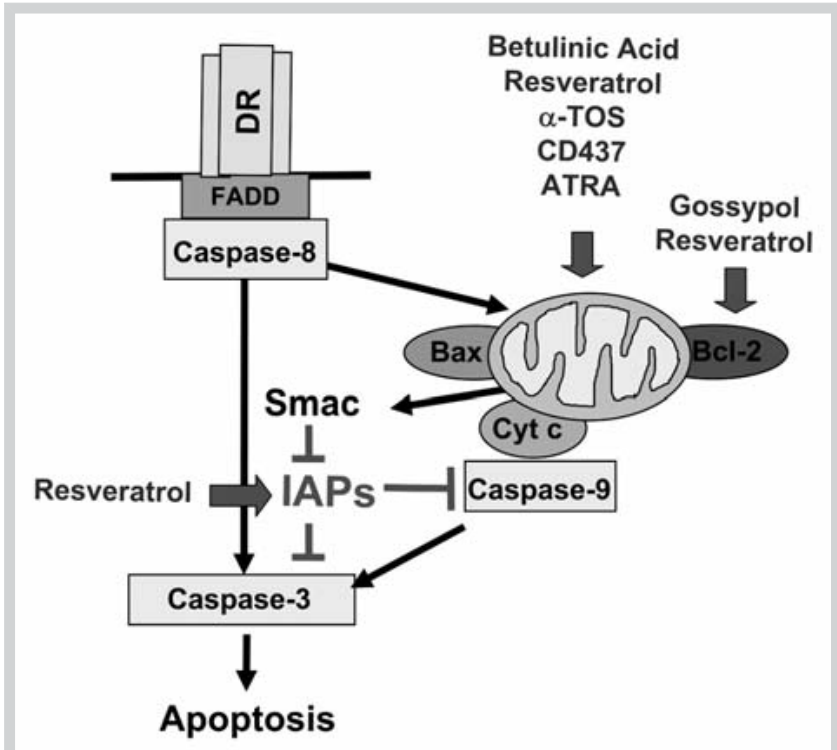

Fig. 2 Modulation of apoptosis pathways by natural compounds. The extrinsic (death receptor) pathway is stimulated by ligation of death receptors (DR) by their respective ligands, which leads to receptor trimerization, recruitment of adaptor molecules (FADD) and activation of caspase-8. The intrinsic (mitochondrial) pathway is initiated by the release of mitochondrial proteins such as cytochrome c or Smac into the cytosol. Natural compounds modulate apoptosis signaling at various points, e.g., at mitochondria by targeting the permeability transition pore complex (e.g., CD437, betulinic acid), by interacting with the ubiquinone-binding sites in respiratory complex II ( $\alpha$-TOS), as ANT ligand (ATRA), by suppression of IAP proteins (resveratrol) or by inhibition of anti-apoptotic Bcl-2 proteins (gossypol, resveratrol). See text for more details. enine nucleotide translocase (ANT) in the mitochondrial inner membrane, hexokinase (HK), which interacts with the mitochondrial outer surface from the cytosol, and cyclophilin D, which is localized in the mitochondrial matrix [10]. The sustained opening of the PTPC coupled with the loss of interactions with HK favors the loss of the mitochondrial membrane potential leading to an osmotic imbalance and swelling of the mitochondrial matrix, a phenomenon called mitochondrial permeability transition (MPT) [10]. This causes the physical rupture of the outer mitochondrial membrane, since the surface area of the inner membrane exceeds by far the surface area of the outer membrane [10]. Components of the PTPC can be targeted by natural products, for example by retinoid-related compounds such as 6-[3(1-adamantyl)-4-hydroxyphenyl]-2-naphthalenecarboxylic acid (CD437) ( Fig. 1) and all-trans-retinoic acid (ATRA). Of note, these retinoids trigger ANT-dependent MPT and subsequently apoptosis independent from their ability to bind to nuclear receptors [45-47].

\section{ROS regulators}

Agents that produce reactive oxygen species (ROS) can trigger mitochondrial outer membrane permeabilization and apoptosis by overwhelming the antioxidant defense of mitochondria and hence causing excessive oxidative damage of mitochondria. One such class of compounds are the dietary phenylethyl isothiocyanates (PEITCS), which inhibit the GSH antioxidant system by conjugating GSH and by inhibiting glutathione peroxidase, lead- 
ing to the production of ROS and subsequently to oxidative damage-mediated mitochondrial apoptosis $[48,49]$. Some estrogen derivatives, e.g., 2-methoxyestradiol, have been described to induce cell death in cancer cells by blocking superoxide dismutase (SOD), an enzyme of the antioxidant defense, thereby increasing ROS generation $[50,51]$.

\section{Agents targeting aberrant metabolism}

Deregulation of mitochondrial functions lies at the intersection between the regulation of cell death events and metabolism [52]. Indeed, metabolic reprogramming is increasingly being recognized as one of the hallmarks of human cancers [52]. Therefore, molecules that are involved in the control of metabolic pathways represent potential targets for the development of new anticancer strategies. Despite high oxygen tension, cancer cells characteristically have an increased glycolytic rate flow, which results in enhanced production of lactate [53]. This phenomenon of aerobic glycolysis is also referred to as the "Warburg effect", as it was first described by Otto Warburg [54]. Hexokinase (HK), the ratelimiting enzyme of glycolysis that catalyzes the conversion of glucose to glucose 6-phosphate, is frequently overexpressed in human cancers and its two isoforms HK1 and HK2 are more tightly bound to VDAC at the outer mitochondrial membrane in cancer cells than in nonmalignant cells [52]. This couples residual ATP production from mitochondria to the rate-limiting step of glycolysis and further promotes the Warburg effect. HK has also been described to exert anti-apoptotic functions by blocking the opening of the permeability transition pore complex (PTPC) due to its ability to bind VDAC [55].

Methyl jasmonate is a plant hormone that has been reported to detach HK from mitochondria via direct interaction, thereby triggering mitochondrial apoptosis [56]. Since HK is expressed at high levels in many human malignancies, targeting HK by methyl jasmonate may provide a means to tackle abnormal metabolism in cancer cells.

\section{Conclusions}

$\nabla$

Natural products of various chemical classes can exert many beneficial effects on human health including the prevention of cancer as well as suppression of tumor growth. These chemopreventive and antitumor activities are mediated, at least to a large extent, via the modulation of cell death pathways including apoptosis in cancer cells. There are multiple intervention points within the apoptotic machinery that have been identified to mediate the antitumor effects of natural compounds, depending on the specific agents. Natural products often exert pleiotropic effects, a feature that may prove to be especially advantageous, as distinct mechanisms of cell death evasion can be simultaneously targeted in cancer cells. Further insights into the molecular mechanisms that mediate the antitumor activities of natural products are expected to promote their development as chemopreventive agents and cancer therapeutics in the ongoing battle against cancer.

\section{Acknowledgements}

$\nabla$

This work has been partly supported by grants from the Deutsche Forschungsgemeinschaft, Deutsche Krebshilfe, Bundesministerium für Bildung und Forschung, Wilhelm-Sander-Stiftung, the
Novartis Stiftung für therapeutische Forschung, the European Community (ApopTrain, APO-SYS), and IAP6/18.

\section{References}

1 Nobili S, Lippi D, Witort E, Donnini M, Bausi L, Mini E, Capaccioli S. Natural compounds for cancer treatment and prevention. Pharmacol Res 2009; 59: 365-378

2 Lockshin RA, Zakeri Z. Cell death in health and disease. J Cell Mol Med 2007; 11: 1214-1224

3 Fulda S. Tumor resistance to apoptosis. Int J Cancer 2009; 124: 511-515

4 Hanahan D, Weinberg RA. The hallmarks of cancer. Cell 2000; 100: $57-$ 70

5 Degterev A, Boyce M, Yuan J. A decade of caspases. Oncogene 2003; 22: 8543-8567

6 Fulda S, Debatin KM. Extrinsic versus intrinsic apoptosis pathways in anticancer chemotherapy. Oncogene 2006; 25: 4798-4811

7 Ashkenazi A. Targeting the extrinsic apoptosis pathway in cancer. Cytokine Growth Factor Rev 2008; 19: 325-331

8 Walczak $H$, Krammer PH. The CD95 (APO-1/Fas) and the TRAIL (APO-2 L) apoptosis systems. Exp Cell Res 2000; 256: 58-66

9 Adams JM, Cory S. The Bcl-2 apoptotic switch in cancer development and therapy. Oncogene 2007; 26: 1324-1337

10 Kroemer G, Galluzzi L, Brenner C. Mitochondrial membrane permeabilization in cell death. Physiol Rev 2007; 87: 99-163

11 Saelens X, Festjens N, Vande Walle L, van Gurp M, van Loo G, Vandenabeele $P$. Toxic proteins released from mitochondria in cell death. Oncogene 2004; 23: 2861-2874

12 LaCasse EC, Mahoney DJ, Cheung HH, Plenchette S, Baird S, Korneluk RG. IAP-targeted therapies for cancer. Oncogene 2008; 27: 6252-6275

13 Okada H, Mak TW. Pathways of apoptotic and non-apoptotic death in tumour cells. Nat Rev Cancer 2004; 4: 592-603

14 Fulda S, Scaffidi C, Susin SA, Krammer PH, Kroemer G, Peter ME, Debatin $K M$. Activation of mitochondria and release of mitochondrial apoptogenic factors by betulinic acid. J Biol Chem 1998; 273: 33942-33948

15 Fulda S, Friesen C, Los M, Scaffidi C, Mier W, Benedict M, Nunez G, Krammer PH, Peter ME, Debatin KM. Betulinic acid triggers CD95 (APO-1/Fas)- and p53-independent apoptosis via activation of caspases in neuroectodermal tumors. Cancer Res 1997; 57: 4956-4964

16 Liby KT, Yore MM, Sporn MB. Triterpenoids and rexinoids as multifunctional agents for the prevention and treatment of cancer. Nat Rev Cancer 2007; 7: 357-369

17 Fulda S, Susin SA, Kroemer G, Debatin KM. Molecular ordering of apoptosis induced by anticancer drugs in neuroblastoma cells. Cancer Res 1998; 58: 4453-4460

18 Andre N, Carre M, Brasseur G, Pourroy B, Kovacic H, Briand C, Braguer D. Paclitaxel targets mitochondria upstream of caspase activation in intact human neuroblastoma cells. FEBS Lett 2002; 532: 256-260

19 Zuco V, Supino R, Righetti SC, Cleris L, Marchesi E, Gambacorti-Passerini $C$, Formelli F. Selective cytotoxicity of betulinic acid on tumor cell lines, but not on normal cells. Cancer Lett 2002; 175: 17-25

20 Salti GI, Kichina JV, Das Gupta TK, Uddin S, Bratescu L, Pezzuto JM, Mehta $R G$, Constantinou AI. Betulinic acid reduces ultraviolet-C-induced DNA breakage in congenital melanocytic naeval cells: evidence for a potential role as a chemopreventive agent. Melanoma Res 2001; 11: 99-104

21 Meng RD, El-Deiry WS. p53-independent upregulation of KILLER/DR5 TRAIL receptor expression by glucocorticoids and interferon-gamma. Exp Cell Res 2001; 262: 154-169

22 Fulda S, Debatin KM. Betulinic acid induces apoptosis through a direct effect on mitochondria in neuroectodermal tumors. Med Pediatr Oncol 2000; 35: 616-618

23 Wick W, Grimmel C, Wagenknecht B, Dichgans J, Weller M. Betulinic acid-induced apoptosis in glioma cells: a sequential requirement for new protein synthesis, formation of reactive oxygen species, and caspase processing. J Pharmacol Exp Ther 1999; 289: 1306-1312

24 Selzer E, Pimentel E, Wacheck V, Schlegel W, Pehamberger H, Jansen B, Kodym $R$. Effects of betulinic acid alone and in combination with irradiation in human melanoma cells. J Invest Dermatol 2000; 114: 935940

25 Gledhill JR, Montgomery MG, Leslie AG, Walker JE. Mechanism of inhibition of bovine F1-ATPase by resveratrol and related polyphenols. Proc Natl Acad Sci USA 2007; 104: 13632-13637

26 Fulda S, Debatin KM. Sensitization for tumor necrosis factor-related apoptosis-inducing ligand-induced apoptosis by the chemopreventive agent resveratrol. Cancer Res 2004; 64: 337-346 
27 Jazirehi AR, Bonavida B. Resveratrol modifies the expression of apoptotic regulatory proteins and sensitizes non-Hodgkin's lymphoma and multiple myeloma cell lines to paclitaxel-induced apoptosis. Mol Cancer Ther 2004; 3: 71-84

28 She Q-B, Huang C, Zhang Y, Dong Z. Involvement of c-jun $\mathrm{NH}(2)$-terminal kinases in resveratrol-induced activation of $\mathrm{p} 53$ and apoptosis. Mol Carcinogen 2002; 33: 244-250

29 Kaneuchi M, Sasaki M, Tanaka Y, Yamamoto R, Sakuragi N, Dahiya R. Resveratrol suppresses growth of Ishikawa cells through down-regulation of EGF. Int J Oncol 2003; 23: 1167-1172

30 Pozo-Guisado E, Lorenzo-Benayas MJ, Fernandez-Salguero PM. Resveratrol modulates the phosphoinositide 3-kinase pathway through an estrogen receptor alpha-dependent mechanism: relevance in cell proliferation. Int J Cancer 2004; 109: 167-173

31 Jiang H, Shang X, Wu H, Gautam SC, Al-Holou S, Li C, Kuo J, Zhang L, Chopp M. Resveratrol downregulates PI3K/Akt/mTOR signaling pathways in human U251 glioma cells. J Exp Ther Oncol 2009; 8: 25-33

32 Shaw RJ, Cantley LC. Ras, PI(3)K and mTOR signalling controls tumour cell growth. Nature 2006; 441: 424-430

33 Biasutto L, Mattarei A, Marotta E, Bradaschia A, Sassi N, Garbisa S, Zoratti $M$, Paradisi $C$. Development of mitochondria-targeted derivatives of resveratrol. Bioorg Med Chem Lett 2008; 18: 5594-5597

34 Constantinou C, Papas A, Constantinou AI. Vitamin E and cancer: an insight into the anticancer activities of vitamin $\mathrm{E}$ isomers and analogs. Int J Cancer 2008; 123: 739-752

35 Dong LF, Low P, Dyason JC, Wang XF, Prochazka L, Witting PK, Freeman $R$, Swettenham E, Valis K, Liu J, Zobalova R, Turanek J, Spitz DR, Domann FE, Scheffler IE, Ralph SJ, Neuzil J. Alpha-tocopheryl succinate induces apoptosis by targeting ubiquinone-binding sites in mitochondrial respiratory complex II. Oncogene 2008; 27: 4324-4335

36 Dong LF, Swettenham E, Eliasson J, Wang XF, Gold M, Medunic Y, Stantic M, Low P, Prochazka L, Witting PK, Turanek J, Akporiaye ET, Ralph SJ, Neuzil J. Vitamin E analogues inhibit angiogenesis by selective induction of apoptosis in proliferating endothelial cells: the role of oxidative stress. Cancer Res 2007; 67: 11906-11913

37 Jia $L$, Yu W, Wang P, Sanders BG, Kline K. In vivo and in vitro studies of anticancer actions of alpha-TEA for human prostate cancer cells. Prostate 2008; 68: 849-860

38 Hahn T, Szabo L, Gold M, Ramanathapuram L, Hurley LH, Akporiaye ET. Dietary administration of the proapoptotic vitamin $E$ analogue alphatocopheryloxyacetic acid inhibits metastatic murine breast cancer. Cancer Res 2006; 66: 9374-9378

39 Lawson KA, Anderson K, Simmons-Menchaca M, Atkinson J, Sun L, Sanders BG, Kline K. Comparison of vitamin E derivatives alpha-TEA and VES in reduction of mouse mammary tumor burden and metastasis. Exp Biol Med (Maywood) 2004; 229: 954-963

40 Neuzil J, Weber T, Schroder A, Lu M, Ostermann G, Gellert N, Mayne GC, Olejnicka B, Negre-Salvayre A, Sticha M, Coffey RJ, Weber C. Induction of cancer cell apoptosis by alpha-tocopheryl succinate: molecular pathways and structural requirements. FASEB J 2001; 15: 403-415

41 Lynn A, Jones L. Gossypol and some other terpenoids, flavonoids, and phenols that affect quality of cottonseed protein. J Am Oil Chem Soc 1979; 56: 727-730

42 Azmi AS, Mohammad RM. Non-peptidic small molecule inhibitors against Bcl-2 for cancer therapy. J Cell Physiol 2009; 218: 13-21
43 Kitada S, Kress CL, Krajewska M, Jia L, Pellecchia M, Reed JC. Bcl-2 antagonist apogossypol (NSC736630) displays single-agent activity in Bcl-2transgenic mice and has superior efficacy with less toxicity compared with gossypol (NSC19048). Blood 2008; 111: 3211-3219

44 Liu G, Kelly WK, Wilding G, Leopold L, Brill K, Somer B. An open-label, multicenter, phase I/II study of single-agent AT-101 in men with castrate-resistant prostate cancer. Clin Cancer Res 2009; 15: 3172-3176

45 Marchetti P, Zamzami N, Joseph B, Schraen-Maschke S, Mereau-Richard C, Costantini P, Metivier D, Susin SA, Kroemer G, Formstecher P. The novel retinoid 6-[3-(1-adamantyl)-4-hydroxyphenyl]-2-naphthalenecarboxylic acid can trigger apoptosis through a mitochondrial pathway independent of the nucleus. Cancer Res 1999; 59: 6257-6266

46 Belzacq AS, El Hamel C, Vieira HL, Cohen I, Haouzi D, Metivier D, Marchetti P, Brenner C, Kroemer G. Adenine nucleotide translocator mediates the mitochondrial membrane permeabilization induced by lonidamine, arsenite and CD437. Oncogene 2001; 20: 7579-7587

47 Notario B, Zamora M, Vinas O, Mampel T. All-trans-retinoic acid binds to and inhibits adenine nucleotide translocase and induces mitochondrial permeability transition. Mol Pharmacol 2003; 63: 224-231

48 Trachootham D, Zhou Y, Zhang H, Demizu Y, Chen Z, Pelicano H, Chiao PJ, Achanta G, Arlinghaus RB, Liu J, Huang P. Selective killing of oncogenically transformed cells through a ROS-mediated mechanism by betaphenylethyl isothiocyanate. Cancer Cell 2006; 10: 241-252

49 Xiao D, Lew KL, Zeng Y, Xiao H, Marynowski SW, Dhir R, Singh SV. Phenethyl isothiocyanate-induced apoptosis in PC-3 human prostate cancer cells is mediated by reactive oxygen species-dependent disruption of the mitochondrial membrane potential. Carcinogenesis 2006; 27: 2223-2234

50 Huang P, Feng L, Oldham EA, Keating MJ, Plunkett W. Superoxide dismutase as a target for the selective killing of cancer cells. Nature 2000 407: 390-395

51 JuarezJC, Manuia M, Burnett ME, Betancourt O, Boivin B, Shaw DE, Tonks NK, Mazar AP, Donate F. Superoxide dismutase 1 (SOD1) is essential for $\mathrm{H}_{2} \mathrm{O}_{2}$-mediated oxidation and inactivation of phosphatases in growth factor signaling. Proc Natl Acad Sci USA 2008; 105: 7147-7152

52 Kroemer G, Pouyssegur J. Tumor cell metabolism: cancer's Achilles' heel. Cancer Cell 2008; 13: 472-482

53 Brahimi-Horn MC, Chiche J, Pouyssegur J. Hypoxia signalling controls metabolic demand. Curr Opin Cell Biol 2007; 19: 223-229

54 Warburg O, Posener K, Negelein E. Über den Stoffwechsel der Tumoren. Biochem Z 1924: 152: 319-344

55 Abu-Hamad S, Zaid H, Israelson A, Nahon E, Shoshan-Barmatz V. Hexokinase-I protection against apoptotic cell death is mediated via interaction with the voltage-dependent anion channel-1: mapping the site of binding. J Biol Chem 2008; 283: 13482-13490

56 Goldin N, Arzoine L, Heyfets A, Israelson A, Zaslavsky Z, Bravman T, Bronner V, Notcovich A, Shoshan-Barmatz V, Flescher E. Methyl jasmonate binds to and detaches mitochondria-bound hexokinase. Oncogene 2008; 27 : 4636-4643

57 Kitada S, Leone M, Sareth S, Zhai D, Reed JC, Pellecchia M. Discovery, characterization, and structure-activity relationships studies of proapoptotic polyphenols targeting B-cell lymphocyte/leukemia-2 proteins. J Med Chem 2003; 46: 4259-4264 